\title{
Reviewing morphology of Quadriceps femoris muscle
}

\author{
CHAVAN, S. K.* and WABALE, R. N. \\ Department of Anatomy, Rural Medical College, Pravara Institute of Medical Sciences, \\ At.post: Loni- 413736, Tal.: Rahata, Ahmednagar, India. \\ *E-mail: sushama_chavan1980@yahoo.com
}

\begin{abstract}
Purpose: Quadriceps is composite muscle of four portions rectus femoris, vastus intermedius, vastus medialis and vatus lateralis. It is inserted into patella through common tendon with three layered arrangement rectus femoris superficially, vastus lateralis and vatus medialis in the intermediate layer and vatus intermedius deep to it. Most literatures do not take into account its complex and variable morphology while describing the extensor mechanism of knee, and wide functional role it plays in stability of knee joint. It has been widely studied clinically, mainly individually in foreign context, but little attempt has been made to look into morphology of quadriceps group. The diverse functional aspect of quadriceps group, and the gap in the literature on morphological aspect particularly in our region what prompted us to review detail morphology of this group. Method: Study consisted dissection of 40 lower limbs (20 rights and 20 left) from 20 embalmed cadavers from Department of Anatomy Rural Medical College, PIMS Loni, Ahmednagar (M) India. Results: Rectus femoris was a separate entity in all the cases. Vastus medialis as well as vastus lateralis found to have two parts, as oblique and longus. Quadriceps group had variability in fusion between members of the group. The extent of fusion also varied greatly. The laminar arrangement of Quadriceps group found as bilaminar or trilaminar. The insertion level of vastus medialis and vastus lateralis on patella varied greatly. Vastus lateralis found to extent to whole extent of lateral border of patella. The extension of fibrous band like structure from lower horizontal fibers of vastus medialis to adductor tubercle also noticed in one case. Conclusion: There is wide variability in the quadriceps group of muscles that we came across, then believed. This variability in the quadriceps group might affect the stability of the knee joint but needs, to prove clinically. The finding may also help in the understanding the factors associated with anterior knee pain and its management.
\end{abstract}

Keywords: Quadriceps, vastus medialis oblique, vastus medialis longus, vastus lateralis longus, laminar arrangement, extent of insertion.

\section{Introduction}

Quadriceps muscle is composed of four parts namely rectus femoris, vastus medialis, vastus lateralis and vastus intermedius. The composite muscle inserted through common tendon on patella and through it to the smooth part of tibial tuberosity. The common tendon has three layered arrangement, rectus femoris (RF) superficially, vastus lateralis (VL) and vastus medialis $(\mathrm{VM})$ in the intermediate layer and vastus intermedius (VI) deep to it (WALIGORA, JOHANSON and HIRSCH, 2009). Vastus Medialis has been described as having two discrete parts the vastus medialis oblique (VMO) and vastus medialis longus (VML) (LIEB and PERRY, 1968). There are also two parts of VL, the vastus lateralis oblique (VLO) and vastus lateralis longus (VLL) described by (SCHARF, WEINSTABL and FIRBAS, 1986) for the first time. All muscles in the group cause extension at the knee except RF that is also a flexor at the hip joint. Quadriceps femoris (QF) muscle group, the producer of extension at knee is three times stronger than its antagonistic group, the hamstrings because it is involved in negatively accelerating the leg and continuously acting against gravity. By its extension to tibial tuberosity it contribute to stability of patella. As a muscle group, they also pull the menisci anteriorly in extension via meniscopatellar ligament. When they contract, they also reduce the strain in medial collateral ligament. Working with posterior cruciate ligament prevents posterior displacement of tibia. The strongest of the group represented by VL apply lateral force to patella. As a whole VM is extensor, VMO is medial stabilizer of patella. RF of the quadriceps group works as knee extensor only when hip joint is in extension, by lengthening the rectus femoris (HAMILL and KNUTZEN, 2009).In activities of daily living contraction of QF required primarily to raise and lower the weight of body while upright. Such activities include getting in and out of chair or climbing stairs (OATIS, 2009).

The line of traction of these muscles is along the axis of femur but is not in line with tibia. It results in the tendency to displace the patella in lateral direction (PEELER, COOPER, PORTER et al., 2005). This is prevented by three morphological formations. The expanded anterior surface on the lateral condyle of the femur behaves like a buttress preventing lateral displacement of patella. Secondly, the pull of medial extensor retinacula also said to resist lateral pull and the third factor is the stabilization imparted to patella by horizontal fibers of VMO (OATIS, 2009). In spite of that, the Patellar instability is one of the common problems that orthopaedician come across. Patellar instability, including sub-luxation, relates to the imbalance of the soft tissues. Atrophy, (WILLAN, MAHON and GOLLAND, 1990) weakness, (FARAHMAND, SEJIAVONGSE and AMIS, 1998) a more proximal attachment 
of the VMO (FULKERSON, 2004) and overdevelopment of the VL (HUGHSTON, WALSH and PUDDU, 1984) have been suggested as causes of patella-femoral dysfunction. Considering the two parts of VL as VLO and VLL, (HALLISAY, DOHERTY, BENNETT et al., 1987) stressed the importance of surgically releasing this muscle to reduce the lateral tension on the patella.

Recently the QF complex is been the subject of renewed interest with regard to histological composition, the anterior lateral part of the muscle frequently chosen for electromyography and skeletal muscle biopsy (SWASH and SCHWARTZ, 1997). Most biopsy samples from VL show considerable variation in muscle fiber size and fiber type proportions between individuals and even between samples from the same individual (MAHON, TOMAN, WILLAN et al., 1984). It is interesting to note that Edgerton, Smith, and Simpson (1975) showed quantitative histological differences between samples from VL and the underlying VI (WILLAN, MAHON and GOLLAND, 1990). Amongst the various group of muscles, the Quadriceps group considered to have least variations (STANDING, COLLINS, CROSSMAN et al., 2008). This group is crucial for stability of knee joint in all possible knee joint positions, since it is active in both extension as well as controlled flexion. We thought it essential to explore detailed morphology of this muscle considering its massive presence on anterior aspect of thigh. As well as its varied functional and clinical aspects and paucity of literature on detailed morphology of quadriceps group in Indian populations, hence this study was undertaken.

\section{Materials and Method}

The study carried out in Department of Anatomy, Rural Medical College, Pravara institute of Medical Sciences, Loni, Ahmednagar (M) India. The study material consisted lower limbs of 20 human unclaimed cadavers in whom the cause of death could not be ascertained. The cadavers were fixed in embalming fluid. Eighteen were male cadavers and two were female cadavers with an age in the range of 60 years and above. Total lower limbs dissected were 40;20 of right and 20 of left side. The limbs that were in straight position and devoid of any obvious pathology were included in the study. Limbs that with distorted or had any scar marks were excluded from study.

Dissection of thigh region from inguinal ligament to the tibial tuberosity was done to explore the quadriceps. After removal of skin and superficial fascia, fascia lata incised and cleared. Ilio tibial tract was exposed cut transversely in middle and flaps reflected upward and downward. Inter muscular spaces were freed from fat and fascia. Anterior part of thigh examined to confirm the presence of four parts of QF muscle, composite pattern, fusion, and insertion of four parts of quadriceps group, existence of VMO and VML, and the presence of VLL and VLO observed and noted.

\section{Results and Discussion}

Quadriceps group of muscle covers the anterior and lateral aspect of the thigh. An extensor at knee QF is very important to generate power in the lower extremity for any form of human translation. RF of the group called the kicking muscle because it is at maximum position for output at the hip during preparatory phase of kick, when thigh is brought back into hyperextension at hip and leg is fixed at knee (HAMILL and KNUTZEN, 2009).

In climbing stairs after the limblift initiations by iliopsoas, RF becomes active to flex the thigh and eccentrically slow the knee flexion. In pull-up phase in which limb is placed on the upper step, extension in the knee joint is brought about by quadriceps of the same side to bring body to that step (HAMILL and KNUTZEN, 2009).

There is considerable muscle activity in multiple muscles during running. At knee joint, both hamstring and quadriceps are active during stance phase. The heel strike phase in running is followed by activation of $\mathrm{QF}$, which initially act eccentrically to slow the negative verticals of body velocity, this action lasts till mid support phase. The QF then act concentrically to produce positive vertical velocity of body, both hamstring and QF is active to generate extension at hip. In propelling phase of support, quadriceps is eccentrically active as the heel lifts off and then becomes concentrically active up through toe-off phase. During initial portion of swing phase, quadriceps is active eccentrically to slow rapid knee flexion (HAMILL and KNUTZEN, 2009).

In walking, after the arrest of movement at the hip joint at heel strike, the quadriceps begins to contract to control weight imposed on knee joint by the body and by the reaction force coming up from ground, the knee moves into flexion eccentrically controlled by the QF. Co-contraction of QF and hamstring continues until foot is flat on ground. The activity of $\mathrm{QF}$ diminishes at $30 \%$ of stance. During late swing phase, quadriceps becomes active which slows knee flexion after toe-off, and initiate knee extension prior to heel strike (HAMILL and KNUTZEN, 2009).

In cycling, the $\mathrm{QF}$ is very active from 0 to $90^{\circ}$. $\mathrm{RF}$ is active through arch of 200 to $130^{\circ}$ of next cycle. VM is active from 300 to $135^{\circ}$ and $\mathrm{VL}$ is active from 315 to $130^{\circ}$ of next cycle. From 270 to $360^{\circ}$ the RF is actually involved as the leg brought up into top position (HAMILL and KNUTZEN, 2009).

In our study in all the specimen four parts of quadriceps group, were recognized easily. RF was a separate entity in all of the 40 limbs. None of the specimen showed fusion (HAMILTON, 1976) of RF with VM and VL. The tendon of RF receives VM and VL on either side $5 \mathrm{~cm}$ above the superior border of patella and inserted on the latter. It remains separate from the other heads within a fascial sheath, controls the relationships between lower back, pelvis, hip, and the knee (FOURIE, 2010) VL was the bulkiest muscle of the group that we observed. VL in its distal one fourth was tendinous in all the specimens though anterior edge varied in its form. The Table 1 shows the variation in the anterior edge of VL. Anterior edge was fleshy in 45\% cases on right side and 30\% cases on left side. Tendinous anterior edge found in $35 \%$ cases on right and $40 \%$ cases on left side. It was independent of the fusion between the VM, VL, and VI. (WILLAN, MAHON and

Table 1. Nature of anterior edge of Vastus Lateralis.

\begin{tabular}{lccccc}
\hline \multirow{2}{*}{\multicolumn{1}{c}{ Nature }} & \multicolumn{2}{c}{ Right } & & \multicolumn{2}{c}{ Left } \\
\cline { 2 - 3 } \cline { 5 - 6 } & No & \% & & No. & $\%$ \\
\hline Fleshy & 9 & 45 & & 6 & 30 \\
Tendinous & 7 & 35 & & 8 & 40 \\
Musculotendenous & 4 & 20 & & 6 & 30 \\
Total & 20 & 100 & & 20 & 100 \\
\hline
\end{tabular}


GOLLAND, 1990) In their study found the anterior medial edge of the distal half of VL to be predominantly fleshy in $22(29 \%)$ limbs, where as in $28(37 \%)$ there was an anterior tendinous lamina wider than $5 \mathrm{~mm}$.

Two distinct parts of VL observed in seven cases (35\%), these are vastus lateralis longus (VLL) and vastus lateralis oblique (VLO). In all these cases, the plane of separation between VLL and VLO was fibro fatty tissue. (Figure 1) The plane of separation between VLL and VLO more pronounced, than the plane of separation between VML and VMO. VLO found in distal portion of VLL. Origin of VLO was from lateral intramuscular septum. In two specimens, VLO also found to attach to tensor fascia lata. (LAST, 1952), reported that not all fibers of VL originated from the femur, a considerable muscle of the lower portion of this muscle originates directly from lateral intramuscular septum. The tendinous sheath of VLO was passing deep to the tendon of VLL, to insert over the supero-lateral aspect of patella. The fibers of VLO were running more horizontal making an angle with VLL fibers. The angular terminal insertion of the VLO related to the longitudinal axis of the patella is more horizontally oriented in males than in females (BENNETT, DOHERTY, HALLISEY et al., 1993). These fibers believed to be important because they provide a more direct lateral pull on the extensor mechanism, (FULKERSON, 2004) as they have a more lateral insertion on the patella than the longitudinal head of the VL (FARAHMAND, SEJIAVONGSE and AMIS, 1998). Therefore, these fibers can play a greater role in patellar stabilization (RUSSELL, WOODBURNE, 1983). Vastus lateralis oblique (VLO) insertion angle predicted upon by measurement of the vastus medialis oblique (VMO) insertion angle and sex (BENNETT, DOHERTY, HALLISEY et al., 1993). The angular terminal insertion of the VLO related to the longitudinal axis of the patella is more horizontally oriented in males than in females

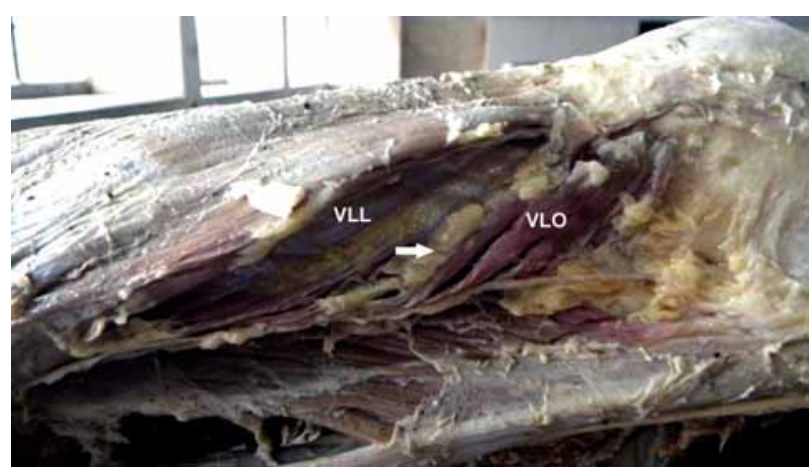

Figure 1. VLO and VLL separated by fibro-fatty tissue (white arrow) VLO-vastus lateralis oblique VLL- vastus lateralis longus. $\log \mathrm{VLO}=1.36+.00531 \mathrm{VNIO}-0.000166(\mathrm{~S} \times \mathrm{VMO})$, where $S=1$ for females and $S=0$ for males (BENNETT, DOHERTY, HALLISEY et al., 1993).

Some authors recognize the clinical importance of the VLO in patellar stability and the maintenance of balance in patella-femoral joint along with the VMO. Considering these portions i.e. VLO and VMO in both, the VL and the VM, as independent muscles, contributing to patellar alignment some author suggested the inclusion of the words: oblique vastus lateralis and vastus medialis oblique in Nomina Anatomica (VIEIRA, 2011). More recently, VL have been divided into four parts based on its architect and innervations as superficial proximal, deep proximal, central, and deep distal partition (BECKER, BAXTER and WOODLEY, 2010).

In one, case on left limb (Out of 40) shows an additional fleshy belly of VL. Proximally it attached to anterior aspect of shaft of femur and distally its tendon joined to VL thus contributing to Quadriceps tendon. Willan, Mahon and Golland (1990) identified an additional fleshy lamina between VL and VI in $27(36 \%)$ thighs, bilateral in 10 subjects, unilateral in seven.

Table 2 shows the insertion of VL at various levels on patella The VL is inserted into the superior and upper one-third part of lateral border of patella, (DATTA, 2004) may extend down the lateral border of patella (VIEIRA, 2011). In the present study, conventional description only accounts for $30 \%$ cases on right and $20 \%$ cases on left side. Most of the cases show insertion on upper two third aspects of lateral border of patella, $60 \%$ on right, and $65 \%$ on left. The insertion extended to whole extent of lateral border, $10 \%$ on right, and $15 \%$ on left. That means $70 \%$ on right and $80 \%$ on left the insertion level of VL found quite distally, which adds to the natural tendency of lateral displacement of patella. In other study, significant difference in angle of insertion of VLL and VLO observed between men and women (HALLISAY, DOHERTY, BENNETT et al., 1987).

VM, one of the three vasti that forms bulk of the lower medial part the Quadriceps group, has proximal part and distal part. The proximal and distal fibers are described as VMO and VML (LIEB and PERRY, 1968) In the present study proximal part of muscle had a straight course and the muscle fibers lay deep to the distal muscle fibers that passed superficial and almost horizontally. The difference in muscle fibers direction suggests difference in function of the each part of VM (ONO, BOOKSTEIN and KANAI, 2005). The plane of separation was at the level of the crossing of superficial distal fibers and deep proximal fibers. This line corresponds to the attachment of superficial horizontal fibers of VM to the tendon of RF. The boundary is more obvious and easy to assess. Therefore, muscle fiber arrangement could distinguish the VMO and VML. (Figure 2) The boundary of the distal and proximal part of VM described to be the line from adductor hiatus to

Table 2. Insertion level of Vastus Medialis and Vastus Lateralis on patella.

\begin{tabular}{|c|c|c|c|c|c|c|c|c|c|c|c|c|}
\hline \multirow{3}{*}{ Extent } & \multicolumn{6}{|c|}{ Vastus Medialis } & \multicolumn{6}{|c|}{ Vastus Lateralis } \\
\hline & \multicolumn{2}{|c|}{ Right } & \multicolumn{2}{|c|}{ Left } & \multicolumn{2}{|c|}{ Total } & \multicolumn{2}{|c|}{ Right } & \multicolumn{2}{|c|}{ Left } & \multicolumn{2}{|c|}{ Total } \\
\hline & No. & $\%$ & No. & $\%$ & No. & $\%$ & No. & $\%$ & No & $\%$ & Total & $\%$ \\
\hline Upper $1 / 3$ & 4 & 20 & 4 & 20 & 8 & 20 & 6 & 30 & 4 & 20 & 10 & 25 \\
\hline Upper $2 / 3$ & 12 & 60 & 13 & 65 & 25 & 62.5 & 12 & 60 & 13 & 65 & 25 & 62.5 \\
\hline Whole & 4 & 20 & 3 & 15 & 7 & 17.5 & 2 & 10 & 3 & 15 & 5 & 12.5 \\
\hline Total & 20 & & 20 & & 40 & & 20 & & 20 & & 40 & \\
\hline
\end{tabular}


the medial rim of patella (ONO, BOOKSTEIN and KANAI, 2005 ), this seems to be difficult to assess.

Plane of separation between VML and VMO is in the form of a fascia, (Figure 2) nerve (Figure 3 ) or is vasculo-fascial in nature (Table 3 ). Separate nerve supply traced for VMO in 10 cases bilateral and 3 cases unilateral. In 70\% cases of right limbs plane of separation existed in the form of fascia in $30 \%$, nerve in $25 \%$ or vasculo fascial in $15 \%$ cases. In the left limbs in $65 \%$ cases, a definite separation was present. It was fascial in $35 \%$, nerve in $20 \%$ and vasculo-fascial in $10 \%$ cases. In $30 \%$ cases on right and $35 \%$ cases on left there was no plane of separation between VMO and VML. These cases may be due to difficulty in getting the plane of separation in VML and VMO and therefore cannot say that it really does not exist. The distal part of VM muscle is fleshy as compared to the VL muscle whose distal part is tendinous and covered by fat and fascia. The distribution and placement of fat pads, fatty tissue layers, and loose areolar tissue layers between anatomical structures has clinical relevance in that they function as "functional bursae" to reduce friction between moving parts, thus contributing to the quality and ease of movement (FOURIE, 2010).

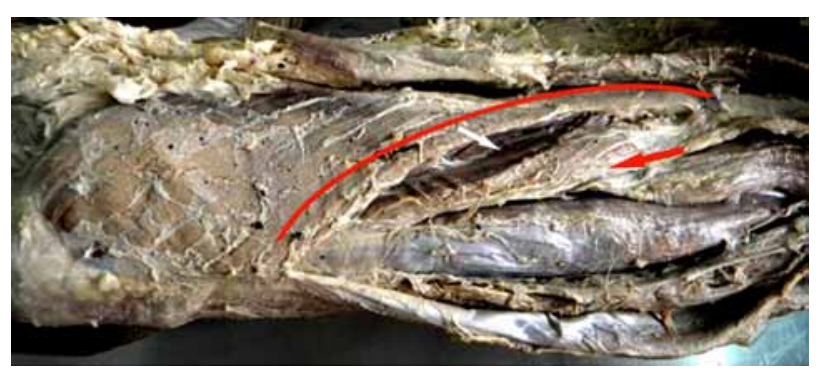

Figure 2. (a) Direction of muscle fibers of VMO and VML (red curve and red arrow); (b) fascial plane (white arrow) of separation between VMO and VML. VMO-vastus medialis oblique VML- vastus medialis longus.

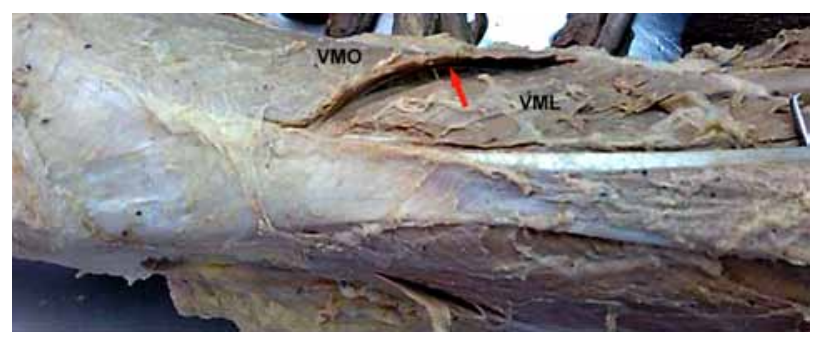

Figure 3. Plane of separation between VMO and VML -nerve (red arrow) VMO-vastus medialis oblique VML- vastus medialis longus.

Table 3. Plain of separation of Vastus Medialis Olique and Vastus Medialis Longus.

\begin{tabular}{lcccccc}
\hline \multirow{2}{*}{$\begin{array}{c}\text { Plain of } \\
\text { separation }\end{array}$} & \multicolumn{2}{c}{ Right } & & \multicolumn{2}{c}{ Left } \\
\cline { 2 - 3 } \cline { 5 - 6 } No separation & 5 & 25 & & 5 & No. & $\%$ \\
Fascial & 7 & 35 & & 8 & 40 \\
Nerve & 5 & 25 & & 7 & 35 \\
Vasculo-fascial & 3 & 15 & & 0 & 0 \\
Total & 20 & $100 \%$ & & 20 & $100 \%$ \\
\hline
\end{tabular}

Most literature describes the insertion of VM on the superior medial aspect of patella, extending over the medial border of patella up to upper two third portions, lower than that of the insertion of VL (HOLLINSHED, 1985) (Table 2). We have found variable extent of insertion of VM on medial border of patella. In $80 \%$ cases, the insertion extended to the upper two third $(60 \%)$ or whole $(20 \%)$ of medial margin of patella. In another $20 \%$ cases, the extent is higher than what has been described. If correlated functionally, these cases may be more susceptible to anterior knee pain due to inability on the part of muscle to counteract the normal lateral traction exerted by Quadriceps tendon.(HOLT, NUNN, ALLEN et al., 2008) assessed population variation of the VMO insertion to the patella by sixty-five magnetic resonance imaging studies and on 18 cadaver specimens. The VMO insertion expressed as a percentage of patellar length. In the magnetic resonance imaging cohort, the mean insertion was $51 \% ; 59 \%$ of individuals had an insertion within $40 \%$ to $60 \%$, with $25 \%$ being distal to $60 \%$. In the cadaveric study, mean insertion was $52 \%$. Both groups displayed a Gaussian distribution.

In one case, VMO had an additional attachment extending from its lateral angle to the tendinous fibers of adductor magnus and probably to adductor tubercle. This was in the form of thick fibrous band. (Figure 4) Functionally this could reinforce the VMO in pulling the patella medially to stabilize the patella against the lateral traction of VL muscle. It has been described that VM- medially has attachments into the distal tendon and fascia of adductor magnus, the fascia over it continues medially forming the fascial sheath and network for the pes anserinus (FOURIE, 2010).

Table 2 shows the comparison between insertion of VM and VL on medial and lateral border of patella. The insertion level of VL appears to be more variable than insertion level of VM in comparison to the conventional description. Only $25 \%$ of VL inserts to upper one third of lateral border of patella. Rests $75 \%$ are variable either inserted on upper two third parts in $62.5 \%$ or to whole extent of lateral border of patella seen in 12.5 percentage cases.

VM is inserted on upper one-third parts in 20\% cases, upper two third parts in $62.5 \%$ cases and whole extent in $12.5 \%$ cases (out of 40 cases). Particularly the distal insertion of VL on the lateral border and the associated higher insertion of VM on medial border of patella can result in imbalance between muscular exert on patella leading to instability and anterior knee pain apart from other causes that have mentioned. It can be said that these cases may be more vulnerable and need to be studied looking at its clinical aspect.

Insertion of VM and VL in nine cases had symmetrical insertion level on upper two third part, two cases in upper one-third part, and two cases in whole extent of medial and lateral border of patella. Sixty-five percent cases were bilaterally symmetrical. In our observation VL insertion is much variable. In $75 \%$ cases, there is distal insertion of VL on lateral border of patella.

Extent of fusion between three vasti was studied Table 4 and we found that in 28 cases out of the forty limbs, VL was fused to VM to a variable extent from lower $3 / 4$ aspect to lower $1 / 2$ or to lower $1 / 4$ th part. In seven cases fusion extended to $3 / 4$ th part, in nine cases, it was seen in $1 / 2$ parts and in 12 cases; it was seen in lower $1 / 4$ th part. In seven cases, VL was found to fuse with VI and fusion was almost in the lower $3 / 4$ th part while VM was fused to VI in five cases. (GOLLAND, MAHON and 
Table 4. Fusion of three Vasti with each other.

\begin{tabular}{|c|c|c|c|c|}
\hline Fusion of VL with VM & Right side & $\%$ & Left side & $\%$ \\
\hline \multicolumn{5}{|c|}{ Fusion of VL with VM } \\
\hline Lower $3 / 4^{\text {th }}$ & 3 & 20 & 4 & 30.77 \\
\hline Lower $1 / 2$ & 5 & 33.33 & 4 & 30.77 \\
\hline Lower $1 / 4$ & 7 & 46.67 & 5 & 38.46 \\
\hline Total & 15 & 100 & 13 & 100 \\
\hline \multicolumn{5}{|c|}{ Fusion of Vastus Intermedius with VM or VL } \\
\hline Fuser with VL & 3 & 60 & 4 & 57.14 \\
\hline Fusion with VM & 2 & 40 & 3 & 42.86 \\
\hline Total & 5 & 100 & 7 & 100 \\
\hline Total cases & 20 & & 20 & \\
\hline
\end{tabular}

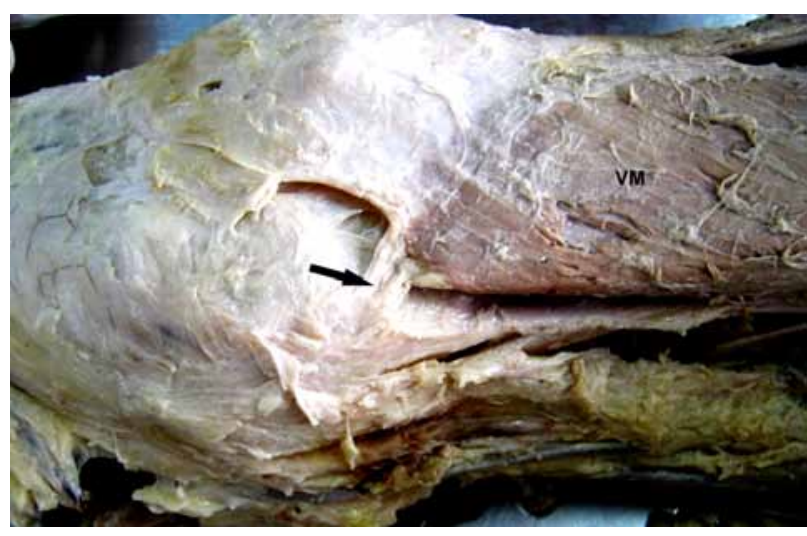

Figure 4. Additional attachment of VM to adductor tubercle through fibrous band (black arrow) VM-vastus medialis.

WILLAM, 1986) assessments of the distal halves of transversely sectioned thighs revealed that there was fusion of more than three quarters of the deep surface of VL with VI in 25 (33\%) limbs, whereas less than one quarter of deep surface was fused in 18 (24\%) limbs. Different degrees of fusion between pair's results in sample error in biopsy of VL muscle. On the other hand, there may be histological differences in vasti from right and left sides were identified in 18 (51\%) cadavers. The differences in anterior edge of VL or differences of fusion between the quadriceps group, and variability in extent of fusion can result in difference in the sample taken from particular site, from the same or from different individual (WILLAN, MAHON and GOLLAND, 1990). Therefore, it can result in difference in histological picture or electromyography study.

We also found the insertion of quadriceps group in laminar pattern. Laminae were arranged either in bilaminar or trilaminar fashion. Bilaminar pattern was observed in eight cases on right and seven cases on left. Trilaminar arrangement was found in eight cases on right and nine cases on left. Out of these two cases were bilaterally bilaminar and five cases were bilaterally trilaminar. Laminar pattern could not be established due to its complexities in five cases on left and three cases on right.

These anatomic differences focus the need to evaluate the clinical consequences of these differences, because differences in the laminations and insertion levels of the quadriceps into the patella could affect patellar movement through differences in the angle and magnitude of the forces acting on it and thus are a predisposing factor for Patello-femoral joint dysfunction.

\section{Conclusion}

Quadriceps muscle has a highly variable morphology. The variations are found in vasti particularly in extent of fusion between three vasti, pattern of laminar arrangement and insertion on patella and laminar arrangement. The VL showed the lower level of insertion on lateral border of patella than the usual description. Plane of separation existed between VML and $\mathrm{VMO}$ in $70 \%$ on right and $65 \%$ on left limb. In one case, an incidental observation of fibrous cord like attachment of lowermost fleshy part of VMO to the adductor tubercle was noted. VL was found in two parts as VLL and VLO. Fibro-fatty tissue separates VLO in seven cases. These observations need to be explore further by more such morphological studies in different regions and clinical aspect needs to be evaluated with respect to variation in morphological picture that is found.

\section{References}

BECKER, I., BAXTER, GDB. and WOODLEY, SJ. The vastus lateralis muscle- an anatomical investigation. Clinical Anatomy (New York, N.Y.), 2010, vol. 23, n. 5, p. 575-585. http://dx.doi.org/10.1002/ ca.20974. PMid:20309954.

BENNETT, WF., DOHERTY, N., HALLISEY, MJ. and FULKERSON, JP. Insertion orientation of terminal vastus lateralis obliquus and vastus medialis obliquus muscle fibers in human knees. Journal Clinical Anatomy, 1993, vol. 6, n. 3, p. 129-134. http://dx.doi. org/10.1002/ca.980060302.

DATTA, AK. Text book of essentials of human anatomy: superior and inferior extremities: part III. 3rd ed. West Bengal: Current Books International, 2004. p. 176-178.

EDGERTON, VR., SMITH, JL. and SIMPSON, DR. Muscle fiber type populations of human leg muscles. The Histochemical Journal, 1975, vol. 7, n. 3, p. 259-266. http://dx.doi.org/10.1007/ BF01003594. PMid:123895.

FARAHMAND, F., SEJIAVONGSE, W. and AMIS, AA. Quantitative study of the quadriceps muscles and trochlear groove geometry related to instability of the patellofemoral joint. Journal of Orthopaedic Research, 1998, vol. 16, n. 1, p. 136-143. http://dx.doi.org/10.1002/ jor.1100160123. PMid:9565086.

FOURIE, WJ. Vastus Medialis and Vastus Medialis Oblique: a new perspective. 2010. Available from: <http/www.wayforward.co.za/ downloads/vastusmedialis $>$. Access in: 20 Dec. 2013.

FULKERSON, JP. Disorders of the patellofemoral joint. 4th ed. Philadelphia: Lippincott Williams and Wilkins, 2004. 
GOLLAND, JA., MAHON, M. and WILLAM, PLT. Anatomical variations in human quadriceps femoris muscles. Journal of Anatomy, 1986, vol. 146, p. 263-264.

HALLISAY, MJ., DOHERTY, N., BENNETT, WF. and FULKERSON, JP. Anatomy of the junction of vastus lateralis tendon and the patella. The Journal of Bone and Joint Surgery. American Volume, 1987, vol. 69, n. 4, p. 545-549. PMid:3571314.

HAMILL, J. and KNUTZEN, KM. Biomechanical basis of human movement: the functional anatomy of lower extremity. $3 \mathrm{rd}$ ed. Philadelphia: Lippincott Williams and Wilkins, 2009. chap. 6, p. 200-243.

HAMILTON, WJT. Extbook of human anatomy. 2nd ed. London: Macmillan, 1976. $184 \mathrm{p}$

HOLLINSHED, WHT. Extbook of anatomy. 6th ed. New York: Harpper and Row, 1985. p. 376-381.

HOLT, G., NUNN, T., ALLEN, RA., FORRESTER, AW. and GREGORI, A. Variation of the Vastus Medialis Obliquus Insertion and its Relevance to Minimally Invasive Total Knee Arthroplasty. The Journal of Arthroplasty, 2008, vol. 23, n. 4, p. 600-604. http://dx.doi. org/10.1016/j.arth.2007.05.053. PMid:18514881.

HUGHSTON, J., WALSH, MM. and PUDDU, G. Patellar subluxation and dislocation. Philadelphia: W.B. Saunders, 1984. p. 1-12. Saunders Monographs in Clinical Orthopedics, vol. v.

LAST, RJ. On the form and structure of muscles. The Journal of Bone and Joint Surgery. British Volume, 1952, vol. 34-B, n. 2, p. 295-305. PMid:12999909.

LIEB, FJ. and PERRY, J. Quadriceps functions: an anatomical and mechanical study using amputed limbs. The Journal of Bone and Joint Surgery. American Volume, 1968, vol. 50, n. 8, p. 1535-1548. PMid:5722849.

MAHON, M., TOMAN, A., WILLAN, PLT. and BAGNALL, KM. Variability of histochemical and morphometric data from needle biopsy specimens of human quadriceps femoris muscle. Journal of the Neurological Sciences, 1984, vol. 63, n. 1, p. 85-100. http://dx.doi. org/10.1016/0022-510X(84)90111-4. PMid:6230417.

OATIS, CA. Knee unit, kinesiology: the mechanics and pathomechanics of human movement. 2nd ed. Philadelphia: Lippincott Williams \& Wilkins, 2009. p. 744-775.
ONO, T., BOOKSTEIN, NA. and KANAI, S. The boundary of vastus medialis oblique and the vastus medialis longus. Phys. Ther. Sci., 2005, vol. 70, n. 1, p. 1-4. http://dx.doi.org/10.1589/jpts.17.1.

PEELER, J., COOPER, J., PORTER, MM., THLIVERIS, JA. and ANDERSON, JE. Structural parameters of the vastus medialis muscle. Clinical Anatomy (New York, N.Y.), 2005, vol. 18, n. 4, p. 281-289. http://dx.doi.org/10.1002/ca.20110. PMid:15832351.

RUSSELL, T. and WOODBURNE, AM. The hip and the thigh: essential of human anatomy. 7th ed. Oxford: Oxford University, 1983. 541 p.

SCHARF, W., WEINSTABL, R. and FIRBAS, W. Anatomische untrsuchungen am streckapparat des kniegelenks und ihreklinische relevanz. Unfallchirur, 1986, vol. 89, p. 456-462.

STANDING S, NEIL R.B, COLLINS P, CROSSMAN A.R, MICHAEL A.G., JEREMIAC C.H., DAVID J.,BVISHY M. RICHARD LM and CAROLINE B.W. Grays anatomy: pelvic girdle and lower limb. 40th ed. London: Churchill Living Stone, 2008. chap. 80, p. 1373-1374.

SWASH, M. and SCHWARTZ, M.S. Neuromuscular diseases A: practical approach to diagnosis and management, muscle and nerve biopsies. London: Springer-Verlag, 1997. chap. 3, p. 43-68.

VIEIRA, EPL. Anatomic study of the portions long and oblique of the vastus lateralis and vastus medialis muscles: review article. Journal of Morphological Science, 2011, vol. 28, n. 4, p. 228-234.

WALIGORA, AC., JOHANSON, NA. and HIRSCH, BE. Clinical anatomy of quadriceps femoris and extensor apparatus of the knee; J. Clinical Orthopaedics and Related Research, 2009, vol. 467, n. 12, p. 3297-3306. http://dx.doi.org/10.1007/s11999-009-1052-y. PMid:19690926.

WILLAN, PLT., MAHON, M. and GOLLAND, JA. Morphological variations of the human vastus lateralis muscle. Journal of Anatomy, 1990, vol. 168, p. 235-239. PMid:2323995. 